\title{
Metodologias Analíticas para o controlo de produtos farmacêuticos
}

\author{
RUI CERDEIRA DE CAMPOS COSTA*
}

A investigação de novas substâncias com actividade terapêutica, bem como de novas aplicações para substâncias activas em circuito comercial, é guiada entre outros factores pela natureza das técnicas analíticas que são utilizadas ao longo deste processo. Na verdade, quanto maior e mais diversificado for o número de recursos analíticos ao dispor das equipas que conduzem os projectos de investigação e desenvolvimento farmacêutico, menor será o tempo necessário para evidenciar as qualidades das substâncias para dar corpo a novas soluções terapêuticas.
Contudo, nem sempre um número elevado ou diversidade de meios analíticos traz sucesso aos projectos. Por vezes, o insucesso é descoberto já numa fase avançada dos projectos, representando para todos quantos neles intervêm uma enorme desilusão. Este artigo procurará, por isso, mostrar de forma mais ou menos sucinta a aplicação dos recursos analíticos ao longo do processo que conduz à descoberta de uma nova substância activa ou de uma nova aplicação para substâncias activas já aprovadas por entidades regulamentares para fins humanos.

\section{Introdução}

O processo que conduz ao aparecimento de uma nova substância com actividade terapêutica (substância activa) é altamente complexo, demorado, dispendioso e frequentemente infrutuoso. A quantidade de informação que é gerada ao longo deste processo depende em larga medida da natureza dos recursos analíticos que estão ao seu dispor.

O desenvolvimento de uma nova substância activa procura na essência processos de síntese capazes de proporcionarem matérias-primas virtualmente puras. Infelizmente, tal desiderato não é possível; na verdade, o mais comum é encontrar um conjunto de impurezas que acompanham a substância activa, cuja natureza e quantidade depende fundamentalmente quer das condições reaccionais que se utilizam durante 0 processo de síntese, quer da estabilidade do produto final face a factores como sejam a temperatura, a humidade, a luz, ou o poder oxidante do meio envolvente.

\footnotetext{
* Laboratório de Desenvolvimento Farmacêutico, Laboratórios Bial, À Avenida Siderurgia Nacional, 4745-457 S. Mamede do Coronado, Portugal
}

Segundo a International Conference on Harmonisation of Technical Requirements for Registration of Pharmaceuticals for Human Use, vulgo $\mathrm{ICH}$, as impurezas que habitualmente podem acompanhar uma substância activa dividem-se em três grupos [1]:

- impurezas inorgânicas;

- solventes residuais;

- impurezas orgânicas.

As impurezas inorgânicas resultam exclusivamente do processo de síntese seleccionado e estão normalmente identificadas; entre elas é possível encontrar reagentes, catalisadores, metais residuais, sais inorgânicos e outros materiais como sejam, e.g., materiais de apoio a processos separativos.

Quanto aos solventes residuais, dado que as reacções que compõem o processo de síntese de uma dada substância activa ocorrem em meio fundamentalmente líquido, é comum no decurso do processo de síntese seleccionado, o recurso a diferentes tipos de líquidos orgânicos ou inorgânicos cuja presença no produto final dificilmente pode ser evitada.
No que diz respeito às impurezas orgânicas, dado que a sua presença no produto final pode resultar quer do processo de síntese, quer da estabilidade da própria substância activa durante a fase de armazenamento, é comum designá-las como impurezas relacionadas quer com o produto final quer com o processo. Estas impurezas podem estar ou não identificadas, podem ser ou não voláteis e podem incluir:

- reagentes de partida;

- intermediários;

- reagentes intermédios, e.g., catalisadores;

- produtos secundários;

- produtos de degradação.

\section{Metodologias para o controlo da substância activa}

Para cada tipo de impureza é necessário estabelecer limites tendo por base considerações de natureza toxicológica. Para algumas das impurezas anteriormente descritas, nomeadamente metais pesados e solventes residuais, a definição desses limites é relativamente mais simples de se estabelecer na medida 
em que existem documentos que, apesar de cariz normativo, propõem limites, que quando cumpridos pelas entidades proponentes de novas substâncias activas, não carecem de justificações adicionais aquando do pedido de autorização para a sua comercialização.

No caso concreto dos solventes residuais, a ICH através da sua guideline Q3C [2-4], agrupa os solventes em três classes, tendo em conta o seu grau de toxicidade; num extremo a classe 1 que inclui os solventes mais tóxicos e para os quais estão definidos limites mais estreitos e cuja utilização deve ser evitada (e.g., benzeno), e no outro a classe 3 que inclui os solventes menos tóxicos e cujos limites são mais largos (e.g., ácido acético). O controlo deste tipo de impurezas é realizado habitualmente por cromatografia gasosa (GC) utilizando diferentes tipos de detectores, sendo os mais comuns, o de ionização de chama (FID) e a espectrometria de massa (MS). Para alguns solventes residuais, especialmente quando evidenciam na sua estrutura grupos com propriedades ácido/base (e.g., ácido acético), é comum o recurso a procedimentos titrimétricos com detecção potenciométrica.

Em relação aos metais, existem igualmente documentos normativos [5] que auxiliam na definição dos limites a impor ao produto final. Para o seu controlo recorre-se com alguma frequência a técnicas colorimétricas e a técnicas de espectroscopia de emissão/absorção atómica (AAS/EAS). O recurso à espectrometria de massa com fonte de plasma (ICP-MS) ou à fluorescência de raios $X$ é considerado quando as espécies podem apresentar teores no produto final que não são passíveis de doseamento pelas outras técnicas anteriormente descritas.

O desenvolvimento das metodologias analíticas a utilizar no controlo de solventes residuais e metais dependem, entre outros factores, da selecção de procedimentos de extracção eficazes destas impurezas. No caso dos solventes residuais, este problema pode ser relativamente obviado através do recurso aos injectores do tipo Headspace, enquanto no caso dos metais a digestão das amostras é um bom procedimento para reduzir a influência da matriz.
A tarefa de estabelecimento de limites máximos para os teores de impurezas orgânicas admissíveis no produto final é relativamente mais complexa, uma vez que depende quer do desempenho do processo sintético em termos de eficácia de purificação da substância activa, quer das características de toxicidade das potenciais impurezas. Por essa razão, a $\mathrm{ICH}$ considera que, sempre que uma impureza apareça na matéria-prima em quantidade superior a 0,15 \% deverá ser qualificada, i.e., deverá avaliar-se o seu potencial toxicológico [1]. Assim, se for estabelecida, por exemplo, uma especificação de 0,30 \% para uma determinada impureza na substância activa, com base na informação disponível sobre o desempenho do processo de purificação, visível através dos resultados obtidos para as primeiras produções, será necessário qualificar essa impureza antes de utilizar-se a substância activa em consideração em ensaios clínicos.

Para além do limite de qualificação, a ICH define outros limites cuja utilização é bastante útil durante o desenvolvimento de uma nova substância activa [1]:

- teores $<0,05 \%$; limite abaixo do qual uma impureza não é considerada para efeitos de cálculo, salvo se a dose diária máxima admissível for superior a 2 g; neste caso o limite a seguir é de $0,03 \%$;

- teores $\leq$ 0,10\%; as impurezas devem ser quantificadas, embora não estejam necessariamente identificadas; quando tal acontece, o doseamento destas impurezas é realizado através do método do padrão externo sendo essa função desempenhada por um padrão da substância activa, ou pelo método da percentagem de área no caso de procedimentos baseados na técnica de cromatografia líquida (HPLC) ou GC. Aquele limite reduz-se para 0,05\% quando a dose diária máxima admissível for superior a 2 g;

- teores > 0,10 \%; as impurezas além de quantificadas deverão estar identificadas.

Com base nas acções que é necessário promover em função dos limites anteriormente indicados é, por vezes, con- veniente especificar um valor menor ou igual a 0,10\%. Deste modo pode obviarse a necessidade de se proceder à identificação e eventualmente qualificação da impureza em questão, salvo se se tratar de um produto com elevada actividade farmacológica utilizado em baixa quantidade, ou se a dose diária máxima admissível for superior a $2 \mathrm{~g}$; neste caso deve seguir-se o limite de 0,05\%.

Dos limites propostos pela $\mathrm{ICH}$ resulta que as metodologias utilizadas para controlar as impurezas deverão ter um limite de quantificação no mínimo de 0,05 \% quando a dose máxima diária de substância activa que pode administrar-se ao humano é inferior a $2 \mathrm{~g}$, e de $0,03 \%$ se a dose for maior do que $2 \mathrm{~g}$.

Habitualmente, o número de impurezas orgânicas que podem acompanhar uma determinada substância activa é superior a 1. Torna-se, por isso, desejável que a sua quantificação e, se possível, a da substância activa, seja realizada recorrendo ao mesmo método analítico. Para que tal seja possível é comum recorrer-se à utilização de técnicas separativas, nomeadamente HPLC, GC ou electroforese capilar (CE), acopladas aos mais diversos sistemas de detecção. 0 desenvolvimento de um método analítico assente numa técnica separativa parte, nestes casos, de duas premissas importantes:

- o método deve proporcionar uma adequada resolução entre os sinais transientes das diferentes espécies a quantificar, para um adequado tempo de corrida;

- o método deve ter a capacidade para quantificar as diferentes impurezas acima de 0,03 ou $0,05 \%$, consoante a dose diária máxima admissível é superior ou inferior a $2 \mathrm{~g}$, respectivamente.

Durante as primeiras fases do desenvolvimento de um novo processo de síntese não se conhecem todas as potenciais impurezas dessa substância activa. Por outro lado, por vezes, as características físico-químicas de algumas impurezas não possibilitam a obtenção de padrões que possam ser utilizados como termo de referência, ou quando possível, a sua síntese conduz a quantidades exíguas. 0 desconhecimento das potenciais impu- 


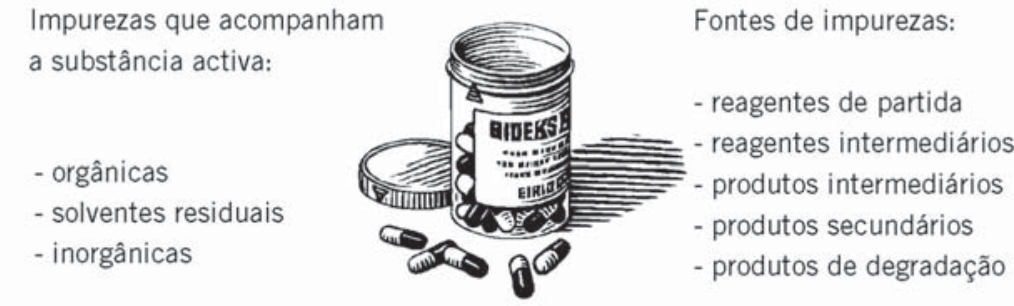

rezas, ou a ausência de padrões destas, dificulta quer o desenvolvimento de um método que apresente um poder de resolução suficientemente adequado para impurezas que são desconhecidas, quer a posterior aplicação do método desenvolvido durante as análises de rotina.

O trabalho de desenvolvimento da metodologia analítica é normalmente realizado através da análise quer de amostras de substância activa sujeitas a condições que proporcionem alguma degradação, quer de padrões de algumas das potenciais impurezas, quando disponíveis, utilizando diferentes técnicas separativas equipadas com diferentes técnicas de detecção e operando com diferentes condições instrumentais, no sentido de encontrar as condições analíticas que proporcionam maior selectividade. A informação retida por cada pico em termos de selectividade pode ser avaliada através da análise da pureza espectral do pico obtido, utilizando como técnica de detecção uma técnica de varrimento, como por exemplo, um detector de díodos ou um espectrómetro de massa. A informação que é recolhida durante esta fase pode ser utilizada em sentido inverso como auxílio na identificação de potenciais novas impurezas.

Todas as metodologias de análise físico-química utilizadas deverão ser sujeitas a validação seguindo as recomendações das guidelines da ICH $[6,7]$.

As dificuldades que surgem durante a fase de aplicação de rotina do método, no que diz respeito à ausência de padrões de algumas impurezas, são contornadas mediante a quantificação das impurezas segundo duas metodologias:

- \% da área do pico de cada impureza relativamente ao somatório das áreas de todos os picos que aparecem no cromatograma; os resultados que se obtêm com esta metodologia podem ser convertidos em \% m/m através da utilização de factores de resposta relativos, i.e., a razão entre as sensibilidades da substância activa e de cada impureza; para impurezas cujo factor de resposta relativo é desconhecido utiliza-se o valor 1 ;

- pelo método do padrão externo, confrontando neste caso os sinais das impurezas observados nos cromatogramas da amostra com os sinais da substância activa presentes nos cromatogramas das soluções padrão, devidamente corrigidos fazendo intervir o factor de resposta relativo de cada impureza.

Para que o método seja capaz de proporcionar um limite de quantificação de pelo menos 0,03 ou 0,05\%, por vezes, torna-se necessário aumentar a quantidade de amostra a analisar, resultando daí, por vezes, perda de linearidade de resposta para a substância activa. Quando isto ocorre, o procedimento analítico deve incluir a análise de soluções diluídas para o doseamento da substância activa e de soluções concentradas para o doseamento das impurezas. Alternativamente, pode recorrer-se a um segundo método, e.g., um procedimento titrimétrico, que apesar de não ser o melhor em termos de selectividade é complementado pelo método utilizado para dosear as impurezas. Caso a substância activa seja um enantiómero será necessário um terceiro método que permita dosear o enantiómero que surge no produto final como impureza. Neste caso concreto, o método deverá incluir na sua descrição um elemento com capacidade de resolução entre enantiómeros. Para os baseados na técnica de HPLC, a separação é conseguida habitualmente por recurso a colunas quirais e menos frequentemente a colunas convencionais de fase reversa utilizando o elemento selector na fase móvel. Para
Figura 1 Tipos e fontes de impurezas que podem surgir no decurso do processo de desenvolvimento de uma nova substância activa

os métodos baseados na técnica de GC a separação é realizada com colunas capilares quirais, enquanto que os métodos electroforéticos baseiam a sua capacidade de resolução no elemento selector incluído no eluente.

As metodologias utilizadas para dosear a substância activa e avaliar a sua pureza são sempre acompanhadas por uma ou mais metodologias de identificação. A espectroscopia de infra-vermelho é talvez a mais utilizada, contudo, é comum também encontrar-se metodologias baseadas na cromatografia em camada fina (TLC), em reacções colorimétricas, ou em reacções de precipitação.

As substâncias activas são também controladas em termos de humidade, habitualmente pela técnica de Karl-Fischer.

Para além dos parâmetros anteriormente referidos é também importante, quando a dimensão da partícula da substância activa tem influência no seu desempenho in vivo, proceder-se à determinação da sua distribuição granulométrica. Esta determinação pode ser realizada entre outras, pela metodologia de difracção de raios $X$ recorrendo à aproximação de Fraunhofer.

A influência no desempenho in vivo pode também resultar da capacidade da substância activa exibir polimorfismo, i.e., a capacidade para cristalizar com diferentes estruturas as quais podem apresentar diferenças em algumas das suas propriedades físico-químicas, nomeadamente solubilidade e estabilidade. Esta característica constitui objecto de estudo nos primeiros estágios do desenvolvimento, mediante o recurso à análise por difracção de raios $X$ e às técnicas de análise térmica como é o caso da calorimetria diferencial de varrimento (DSC). Estes estudos visam identificar não só os possíveis polimorfos de uma determinada substância activa, 
Tabela 1 Alguns exemplos de metodologias analíticas utilizadas para o controlo de impurezas em produtos farmacêuticos.

\begin{tabular}{lll}
\hline \multicolumn{1}{c}{ Solventes residuais } & \multicolumn{1}{c}{ Impurezas inorgânicas } & \multicolumn{1}{c}{ Impurezas orgânicas } \\
\hline - GC-FID & - Técnicas colorimétricas & - Técnicas separativas \\
- GC-MS & - AAS/EAS & (HPLC, GC, Electrofórese ca- \\
- Titrimetria com detec- & - ICP-MS & pilar) acopladas a diferentes \\
ção potenciométrica & - Fluorescência de raio X & tipos de detectores \\
\hline
\end{tabular}

formulado, cuja natureza é definida em função do estado físico do produto, da aplicação e da composição, conforme é possível observar nas farmacopeias, e.g., a Europeia [9] ou a dos Estados Unidos da América [10].

\section{Considerações finais}

Das considerações anteriores é possível verificar que a investigação de novas substâncias com actividade terapêutica, bem como de novas aplicações para substâncias activas já aprovadas para outras aplicações terapêuticas, é guiada em parte pela natureza dos recursos analíticos que são utilizadas ao longo deste processo. Na verdade, quanto maior e mais diversificado for o número de recursos analíticos ao dispor das equipas que conduzem os projectos de investigação e desenvolvimento farmacêutico, mais rapidamente será possível saber se a substância realmente evidencia qualidades para dar corpo a uma nova solução terapêutica. Infelizmente, por vezes, por maior que sejam os recursos e o empenho de todos aqueles que integram as equipas de I\&D, o insucesso só é descoberto já numa fase avançada dos projectos, representando para todos quantos intervêm nos projectos uma grande desilusão. Os projectos de I\&D farmacêuticos são por isso uma corrida contra o tempo, cujo objectivo maior é encontrar o mais rapidamente possível novas soluções terapêuticas que acrescentem valor às que já se conhecem, sempre em concordância com os padrões impostos pelas entidades regulamentares e pelos parceiros comerciais.

\section{Referências}

1 International Conference on Harmonisation of Technical Requirements for Registration of Pharmaceuticals for Human Use, Guideline Q3A(R) - Impurities in
New Drug Substances, ICH, Geneva, 2002.

2 International Conference on Harmonisation of Technical Requirements for Registration of Pharmaceuticals for Human Use, Guideline Q3C - Impurities: Guideline for Residual Solvents, ICH, Geneva, 1997.

3 International Conference on Harmonisation of Technical Requirements for Registration of Pharmaceuticals for Human Use, Guideline Q3C(M) - Impurities: Residual Solvents (Maintenance) PDE for Tetrahydrofuran, ICH, Geneva, 2002.

4 European Medicines Agency, CPMP/ QWP/450/03, Annexes to: CPMP/ICH/283/95 \& CVMP/VICH/502/99, Annex I: Specifications for Class 1 and Class 2 Residual Solvents in Active Substances, Annex II: Residues ff Solvents Used in the Manufacture of Finished Products, EMA, London, 2005.

5 The European Agency for the Evaluation of Medicinal Products, CPMP/SWP/ QWP/4446/00, Note for Guidance on Specification Limits for Residues of Metal Catalysts, EMEA, London, 2002.

6 International Conference on Harmonisation of Technical Requirements for Registration of Pharmaceuticals for Human Use, Guideline Q2A - Text on Validation of Analytical Procedures, ICH, Geneva, 1994.

7 International Conference on Harmonisation of Technical Requirements for Registration of Pharmaceuticals for Human Use, Guideline Q2B - Validation of Analytical Procedures - Methodology, ICH, Geneva, 1996.

8 International Conference on Harmonisation of Technical Requirements for Registration of Pharmaceuticals for Human Use, Guideline Q3B(R) - Impurities in New Drug Products, ICH, Geneva, 2003.

9 Council of Europe, Directorate for the Quality of Medicines of the Council of Europe (EDQM), European Pharmacopoeia, $5^{\text {th }}$ Edition, Strasbourg, 2005.

10 United States Pharmacopeia Convention - Inc, The United States Pharmacopeia 28 - The National Formulary 23, Rockville, 2005. 